\title{
西藏栽培大麦的遗传多样性中心
}

\author{
王建林 胡 单 \\ (西藏农牧学院农学系, 西藏林芝 860000)
}

\begin{abstract}
摘 要 以西藏 3204 份栽培大麦 (Hordeum vulgare) 地方品种为材料, 运用群体遗传学的原理与方法, 研究了西藏 栽培大麦遗传资源的数量、遗传多样性指数和综合变异系数及其生态地理分布特征。结果表明:1) $28^{\circ} \sim 30^{\circ} \mathrm{N} \times$ $88^{\circ} \sim 94^{\circ} \mathrm{E}$ 的藏中地区栽培大麦资源分布广泛, 遗传多样性丰富 综合变异系数高 ,2) $30^{\circ} \sim 31^{\circ} \mathrm{N} \times 96^{\circ} \sim 98^{\circ} \mathrm{E}$ 的藏 东横断山脉地区栽培大麦资源、遗传多样性和综合变异系数次之。并据此提出西藏栽培大麦的遗传多样性中心及 其多样性扩散方式。
\end{abstract}

关键词 西藏 遗传 多样性中心 栽培大麦

\section{A STUDY ON GENETIC DIVERSITY CENTERS OF TIBET CULTIVATED BARLEY}

\author{
WANG Jian-Lin and HU Dan \\ (Agronomy Department , Tibet Agricultural and Animal Husbandry College , Linzhi , Tibet 860000 , China)
}

\begin{abstract}
Tibet is a most beautiful place, located in southwestern China. She has been called" the roof of the world" and " the third pole of the earth" . A combination of unique geological history , complex land surface and climatic zones, various soil types, and different wild vegetation makes Tibet a very typical area of vertical agricultural ecosystem. The ecosystem in Tibet may be the most complex and variable in the world. Unique and complex environments , long agricultural history , different cropping systems, and natural and artificial selection endow Tibetan barely with the richest genetic diversity , which makes Tibet one of the first barley gene centers in the world. Today, whenever and wherever scientists talk about the origin of barley, they always mention Tibet. Since the beginning of this century, Tibet has been drawing attention of scientists from all over the world. Before 1950 , because of the known political reasons , some foreign scientists entered and exploited in some collections of Tibetan barley, but they could not capture the whole range of Tibetan barley resources. After the establishment of P. R. China, the Tibetan social system was changed peacefully, and great progress has been made on research of Tibetan barley germplasms. 3502 accessions of barley germplasm have been collected from Tibet. All of the collections have been cataloged and reserved in the long-term national gene bank. All of these collections have been evaluated and verified on agronomy traits, disease resistance, abiotic stress tolerance, and nutrient content and quality. They were also grouped based on their living habits , botanical and genetic characters. Some elite germplasms were screened out and used in cross breeding programs. Good achievement has been obtained and many high quality papers published. However , the genetic diversity centers and its mode of spread were not studied yet. The author focused on barley genetic diversity centers and its spread mode. The genetic diversity, comprehensive collection of variability of 12 traits and the distribution of 3204 accessions collected from Tibet and quantitative genetic method are presented in this paper. The results show that : 1) cultivated barley in $28^{\circ}-30^{\circ} \mathrm{N} \times 88^{\circ}-94^{\circ} \mathrm{E}$ was highest in accessions, genetic diversity and comprehensive collection of variability ;2) cultivated barley in $30^{\circ}-31^{\circ} \mathrm{N} \times 96^{\circ}-98^{\circ} \mathrm{E}$ of Hengduan Mountains takes second place. The genetic diversity centers and spread modes of genetic diversity were put forward according to the distribution centers, genetic diversity and comprehensive collection of variability.
\end{abstract}

Key words Tibet , Genetic , Diversity centers , Cultivated barley

西藏地处我国西南边陲,介于东经 $78^{\circ} 25^{\prime} \sim$ $99^{\circ} 06^{\prime}$ 北纬 $26^{\circ} 50^{\prime} \sim 36^{\circ} 53^{\prime}$ 之间，土地面积 $1.2284 \times$ $10^{4} \mathrm{~km}^{2}$, 是我国典型的低纬度、高海拔农业区, 素以 “世界屋脊” 和地球 第三极” 著称于世。由于地质史
独特, 地形地貌复杂, 气候带全, 土壤种类繁多, 野生 植被多样, 凡此种种, 西藏高原大麦 (Hordeum vulgare) 生境具有全球最典型的立体生境特色, 其生态 环境千差万别, 堪称全球之最。独特而复杂的大麦 
生境，有悠久的农业历史和多样化的耕作制度，加之 长期的自然选择和人工选择, 产生了丰富多样的大 麦遗传资源, 成为世界栽培大麦的起源中心之一(马 得泉, 2000)。

自 20 世纪 80 年代以来, 在对西藏大麦品种资 源征集与考察的基础上,我国学者对西藏栽培大麦 的性状赋值进行了一些研究(马得泉, 2000, 徐廷文, 1982），并从植物学性状、生化性状、品质化学性状、 抗病性状、农艺性状、生态性状、孢粉学、考古学、分 子生物学等方面进行了多学科分析, 发现西藏栽培 大麦的遗传多样性十分丰富 (傅大雄等, 2000; 吕得 泉等, 1987; 1991; 王恒杰, 1975; 王宗华, 1992; 扎桑 等,1991; 湛小燕等,1991 张启发等,1992)。然而， 植物遗传多样性的地理分布并不是均匀的，在西藏 高原如此广泛的地理环境下, 何处是栽培大麦的遗 传多样性中心, 是大麦研究工作者关注的热点。本 文试图运用群体遗传学原理和方法, 系统地研究西 藏栽培大麦的遗传多样性, 探讨西藏栽培大麦的多 样性中心及多样性扩散，以期进一步确立西藏在世 界大麦起源中心上的地位。

\section{1 研究材料与方法}

\section{1 研究材料}

研究使用的材料为西藏栽培大麦资源数据库编 目材料，包括来自西藏 7 个地区、61 个县的 3204 份 地方品种材料, 基本囊括了西藏各地大麦种植区搜 集和保存的全部栽培大麦地方品种。

\section{2 研究方法}

以西藏栽培大麦资源数据库为基础，将所搜集 的 3204 份材料在 1998 2000 年种植于西藏农牧学 院实习农场, 3 次重复, 随机区组设计, 在生长期间 调查各农艺性状及物候期, 并观察和测定稃型、棱 型、穗密度、冬春性、熟期类型等 5 个质量性状和株 高、穗粒数、千粒重、蛋白质含量、赖氨酸含量及淀粉 含量等 6 个数量性状 将其进行多元统计分析。具 体方法如下：

\subsection{1 性状赋值}

根据徐廷文 (1982)的中国大麦分类系统和马得 泉 (2100) 关于栽培大麦性状的分级研究, 并根据西 藏栽培大麦的实际情况，对参试材料的稃型、棱型、 穗密度、冬春性、熟期类型、株高、穗粒数、千粒重、蛋 白质含量、赖氨酸含量及淀粉含量等 11 个性状中的 5 个质量性状和 6 个数量性状进行赋值 (表 1 )。

\subsection{2 数据正规化处理}

由于所研究的 11 个性状的量纲不同, 所以难 以合并运算,为此, 将原始材料作正规化处理,

表 1 性状赋值

Table 1 Quantified value of qualitative traits

\begin{tabular}{|c|c|c|c|c|c|c|}
\hline $\begin{array}{l}\text { 性状 } \\
\text { Traits }\end{array}$ & $\begin{array}{c}\text { 赋值 } \\
\text { Quantified }\end{array}$ & $\begin{array}{c}\text { 依据 } \\
\text { Foundation }\end{array}$ & $\begin{array}{c}\text { 赋值 } \\
\text { Quantified }\end{array}$ & $\begin{array}{c}\text { 依据 } \\
\text { Foundation }\end{array}$ & $\begin{array}{c}\text { 赋值 } \\
\text { Quantified }\end{array}$ & $\begin{array}{c}\text { 依据 } \\
\text { Foundation }\end{array}$ \\
\hline 稃型 & 有稃 Husked & & 无稃 Naked & & & \\
\hline Husked type & $=1$ & & $=2$ & & & \\
\hline 棱型 & 二棱 2-rowed & & 四棱 4-rowed & & 六棱 6-rowed & \\
\hline Rowed type & $=1$ & & $=2$ & & $=3$ & \\
\hline $\begin{array}{c}\text { 穗密度 } \\
\text { Spike density }{ }^{1)}\end{array}$ & $\begin{array}{l}\text { 稀穗 Lax } \\
=1\end{array}$ & $<14$ & $\begin{array}{l}\text { 密穗 Dense } \\
=2\end{array}$ & $14 \sim 19$ & $\begin{array}{c}\text { 极密穗 Densest } \\
=3\end{array}$ & $>19$ \\
\hline $\begin{array}{c}\text { 冬春性 } \\
\text { Spring and fall type }\end{array}$ & $\begin{array}{c}\text { 春性 Spring type } \\
=1\end{array}$ & & $\begin{array}{c}\text { 冬性 Fall type } \\
=2\end{array}$ & & & \\
\hline $\begin{array}{l}\text { 熟期类型 } \\
\text { Maturity type }\end{array}$ & $\begin{array}{c}\text { 早熟 Early } \\
=1\end{array}$ & $\begin{array}{c}<105 \mathrm{~d} \\
\text { (春性 Spring type) } \\
<280 \mathrm{~d} \\
\text { (冬性 Fall type) }\end{array}$ & $\begin{array}{l}\text { 中熟 Middle } \\
\quad=2\end{array}$ & $\begin{array}{c}105 \sim 120 \mathrm{~d} \\
\text { (春性 Spring type) } \\
280 \sim 290 \mathrm{~d} \\
\text { (冬性 Fall type) }\end{array}$ & $\begin{array}{c}\text { 晚熟 Late } \\
\quad=3\end{array}$ & $\begin{array}{c}>120 \mathrm{~d} \\
\text { (春性 Spring type) } \\
>290 \mathrm{~d} \\
\text { (冬性 Fall type) }\end{array}$ \\
\hline $\begin{array}{c}\text { 株高 } \\
\text { Plant height }\end{array}$ & $\begin{array}{c}\text { 矮 Short } \\
=1\end{array}$ & $<80 \mathrm{~cm}$ & $\begin{array}{c}\text { 中 Middle } \\
=2\end{array}$ & $80 \sim 110 \mathrm{~cm}$ & 高 Tall = 3 & $>110 \mathrm{~cm}$ \\
\hline $\begin{array}{c}\text { 穗粒数 } \\
\text { Kernels/spike }\end{array}$ & $\begin{array}{l}\text { 轻 Light } \\
=1\end{array}$ & $<40$ 粒 Kernel & $\begin{array}{c}\text { 中 Middle } \\
=2\end{array}$ & $\begin{array}{c}40 \sim 80 \text { 粒 } \\
\text { Kernel }\end{array}$ & 重 Weight = 3 & $>80$ 粒 Kernel \\
\hline $\begin{array}{c}\text { 千粒重 } \\
\text { 1000-kernel weight }\end{array}$ & $\begin{array}{c}\text { 小 Small } \\
=1\end{array}$ & $<35 \mathrm{~g}$ & $\begin{array}{c}\text { 中 Middle } \\
=2\end{array}$ & $35 \sim 50 \mathrm{~g}$ & 大 $\mathrm{Big}=3$ & $>50 \mathrm{~g}$ \\
\hline $\begin{array}{c}\text { 蛋白质含量 } \\
\text { Protein content }\end{array}$ & $\begin{array}{l}\text { 低 Low } \\
=1\end{array}$ & $<11 \%$ & $\begin{array}{c}\text { 中 Middle } \\
=2\end{array}$ & $11 \% \sim 16 \%$ & 高 Tall = 3 & $>16 \%$ \\
\hline $\begin{array}{l}\text { 赖氨酸含量 } \\
\text { Lysine content }\end{array}$ & $\begin{array}{l}\text { 低 Low } \\
=1\end{array}$ & $<0.45 \%$ & $\begin{array}{c}\text { 中 Middle } \\
2 \\
\end{array}$ & $0.45 \% \sim 0 . .55 \%$ & 高 Tall = 3 & $>0.55 \%$ \\
\hline $\begin{array}{c}\text { 淀粉含量 } \\
\text { Starch content } \\
\end{array}$ & $\begin{array}{c}\text { 低 Low } \\
=1\end{array}$ & $<60 \%$ & 中 Middle $=2$ & $60 \% \sim 65 \%$ & 高 Tall = 3 & $>65 \%$ \\
\hline
\end{tabular}


令

$$
\chi_{i j}^{\prime}=\frac{\chi_{i j}-\chi_{i_{\text {min }}}}{\chi_{i_{\text {max }}}-\chi_{i_{\text {min }}}}
$$

$\chi_{i_{\max }}$ 为 $i$ 性状中最大的原始赋值数据, $\chi_{i_{\min }}$ 为 $i$ 性 状中最小的原始赋值数据, $\chi_{i j}$ 为第 $i$ 个性状第 $j$ 个品 种的原始赋值数据, $\chi_{i j}^{\prime}$ 为原始赋值数据 $\chi_{i j}$ 的正规 化数据。据此可将所有数量性状及质量性状正规于 $[0,1]$ 的区间中 ,使之便于合并运算。

\subsection{3 小区划分}

把西藏栽培大麦种植区，按 1 个纬度、5 个经度 划分成 43 个分布区。

\subsection{4 遗传多样性指数及变异系数计算}

分别计算每一小区栽培大麦的遗传多样性指数 和 11 个性状 (5 个赋值的质量性状、6 个赋值的数量 性状)的变异系数。

遗传多样性指数 (Shannon-Wiener 指数)：

$$
H^{\prime}=-\sum_{i=1 j=1}^{m} \sum_{i j}^{w} P_{i j} \ln \left(P_{i j}\right)
$$

$m$ 仦区中所观察的性状数; $i$ :小区中第 $i$ 个性状; $w$ 为 $i$ 性状的赋值类型数; $j$ : 为 $i$ 性状的第 $j$ 个赋 值; $P_{i j}$ 小区内第 $i$ 个性状中第 $j$ 个赋值的观察值个 数占 $i$ 性状总赋值个数的比例。

综合变异系数 :

$$
C V=\frac{1}{m} \sum_{i=1}^{m} \sqrt{\frac{S_{i}}{\bar{x}}} \times 100
$$

$m$ 小区中所观察的性状数; $S_{i}$ : 小区中第 $i$ 个性状 所有观察值所赋值正规化数据的标准差; $\bar{x}$ :小区中 第 $i$ 个性状所有观察值所赋值正规化数据的平均 数。

\section{2 结果与分析}

\section{1 西藏栽培大麦地理分布}

西藏栽培大麦在东起金沙江畔、西至阿里高原、 北抵昆仑山脉、南达喜马拉雅山南簏的广阔区域均 有分布。并有从两端纬度向中间逐渐增多的趋势, 特别是北纬 $28^{\circ} \sim 31^{\circ}$ 地区, 品种数量达 2521 个, , 占 西藏栽培大麦 3204 份的 $78.68 \%$ 。另外, 从经度 看, 也有类似趋势。在西起马做木拉山口、东至金沙 江畔的范围内, 随着经度向中间逐渐推移, 品种数量 逐渐增多。在此以外地区, 由于海拔增高、温度降低 或降水稀少等原因, 除个别温、湿度条件较好的局部 地区有大麦栽培外, 其余地区基本没有大麦栽培。

在已搜集的 3204 份栽培大麦品种中，分布范 围为 18 个经度、 9 个纬度。南北从北部 $35^{\circ} \mathrm{N}$ 的阿 里地区日土县至南部 $27^{\circ} \mathrm{N}$ 的山南地区错那县; 东 西从 $98^{\circ} \mathrm{E}$ 的昌都地区芒康县到 $81^{\circ} \mathrm{E}$ 的阿里地区 札达县。搜集范围为 $27^{\circ} \sim 35^{\circ} \mathrm{N} \times 81^{\circ} \sim 98^{\circ} \mathrm{E}$ (表 2 ）。其中集中分布范围为 $28^{\circ} \sim 30^{\circ} \mathrm{N} \times 88^{\circ} \sim 94^{\circ} \mathrm{E}$ 。 从此地区向四周总趋势是逐渐减少, 在北纬 $30^{\circ} \sim$ $31^{\circ} \mathrm{N}, 96^{\circ} \sim 98^{\circ} \mathrm{E}$ 范围内稍有例外。

\section{2 西藏栽培大麦遗传多样性的地理分布}

西藏栽培大麦遗传多样性和群体综合变异系 数, 南北分布基本一致, 随着纬度增大, 出现 3 个多 样性丰富区，分别为 $28^{\circ} \sim 29^{\circ} \mathrm{N} 、 29^{\circ} \sim 30^{\circ} \mathrm{N}$ 和 $30^{\circ} \sim$ $31^{\circ} \mathrm{N}$ 。由此向北或向南，多样性指数逐渐减少。从 东到西出现了 4 个遗传多样性丰富区, 分别为 $96^{\circ} \sim$ $98^{\circ} \mathrm{E} 、 92^{\circ} \sim 94^{\circ} \mathrm{E} 、 90^{\circ} \sim 92^{\circ} \mathrm{E}$ 和 $88^{\circ} \sim 90^{\circ} \mathrm{E}$, 由此向 东或向西, 多样性指数也逐渐减少(表 3 )。

\begin{tabular}{|c|c|c|c|c|c|c|c|c|c|c|c|c|}
\hline \multirow{2}{*}{$\begin{array}{c}\text { 纬度 } \\
\text { Latitude }\end{array}$} & \multicolumn{12}{|c|}{ 经度 Longitude } \\
\hline & $79^{\circ}$ & $80^{\circ} \sim 82^{\circ}$ & $82^{\circ} \sim 84^{\circ}$ & $84^{\circ} \sim 86^{\circ}$ & $86^{\circ} \sim 88^{\circ}$ & $88^{\circ} \sim 90^{\circ}$ & $90^{\circ} \sim 92^{\circ}$ & $92^{\circ} \sim 94^{\circ}$ & $94^{\circ} \sim 96^{\circ}$ & $96^{\circ} \sim 98^{\circ}$ & $99^{\circ}$ & 合计 Total \\
\hline $35^{\circ} \sim 34^{\circ}$ & 2 & 2 & & & & & & & & & & 4 \\
\hline $34^{\circ} \sim 33^{\circ}$ & 3 & 5 & & & & & & & & & & 8 \\
\hline $33^{\circ} \sim 32^{\circ}$ & 4 & 7 & & & & & & & 6 & 11 & & 18 \\
\hline $32^{\circ} \sim 31^{\circ}$ & 9 & 10 & & & & & & 2 & 12 & 34 & 29 & 96 \\
\hline $31^{\circ} \sim 30^{\circ}$ & 2 & 9 & 2 & & & 12 & 29 & 18 & 27 & 278 & 72 & 449 \\
\hline $30^{\circ} \sim 29^{\circ}$ & & & & 20 & 59 & 383 & 481 & 214 & 150 & 78 & 20 & 1405 \\
\hline $29^{\circ} \sim 28^{\circ}$ & & & & 62 & 111 & 301 & 209 & 349 & 42 & 30 & 12 & 1116 \\
\hline $28^{\circ} \sim 27^{\circ}$ & & & & 18 & 35 & & & 30 & & & & 83 \\
\hline $26^{\circ}$ & & & & & & & & 15 & & & & 15 \\
\hline 合计 Total & 20 & 33 & 2 & 100 & 205 & 696 & 719 & 628 & 237 & 431 & 133 & 3204 \\
\hline
\end{tabular}

表 2 西藏栽培大麦资源数量地理分布

Table 2 Geographical distribution of cultivated barley in Tibet (\%) 
表 3 西藏栽培大麦遗传多样性指数地理分布

Table 3 Geographical distribution of genetics diversity index of cultivated barley in Tibet

\begin{tabular}{|c|c|c|c|c|c|c|c|c|c|c|c|}
\hline \multirow{2}{*}{$\begin{array}{c}\text { 纬度 } \\
\text { Latitude }\end{array}$} & \multicolumn{11}{|c|}{ 经度 Longitude } \\
\hline & $79^{\circ}$ & $80^{\circ} \sim 82^{\circ}$ & $82^{\circ} \sim 84^{\circ}$ & $84^{\circ} \sim 86^{\circ}$ & $86^{\circ} \sim 88^{\circ}$ & $88^{\circ} \sim 90^{\circ}$ & $90^{\circ} \sim 92^{\circ}$ & $92^{\circ} \sim 94^{\circ}$ & $94^{\circ} \sim 96^{\circ}$ & $96^{\circ} \sim 98^{\circ}$ & $99^{\circ}$ \\
\hline $35^{\circ} \sim 34^{\circ}$ & 1.12 & 1.89 & & & & & & & & & \\
\hline $34^{\circ} \sim 33^{\circ}$ & 1.39 & 1.94 & & & & & & & & & \\
\hline $33^{\circ} \sim 32^{\circ}$ & 1.83 & 2.05 & & & & & & & 2.65 & 3.37 & \\
\hline $32^{\circ} \sim 31^{\circ}$ & 1.86 & 2.13 & & & & & & 1.45 & 4.08 & 6.33 & 4.83 \\
\hline $31^{\circ} \sim 30^{\circ}$ & 1.53 & 2.39 & 1.08 & & & 4.42 & 4.46 & 4.03 & 5.19 & 7.89 & 6.64 \\
\hline $30^{\circ} \sim 29^{\circ}$ & & & & 2.89 & 4.46 & 7.64 & 8.09 & 5.59 & 6.08 & 6.30 & 5.28 \\
\hline $29^{\circ} \sim 28^{\circ}$ & & & & 4.72 & 5.80 & 4.86 & 3.34 & 8.34 & 5.12 & 5.38 & 4.55 \\
\hline $28^{\circ} \sim 27^{\circ}$ & & & & 4.68 & 3.47 & & & 5.03 & & & \\
\hline $26^{\circ}$ & & & & & & & & 4.27 & & & \\
\hline
\end{tabular}

表 4 西藏栽培大麦资源综合变异系数地理分布 $(\%)$

Table 4 Geographical distribution of synthesis variant cofficient of cultivated barley in Tibet (\%)

\begin{tabular}{|c|c|c|c|c|c|c|c|c|c|c|c|}
\hline \multirow{2}{*}{$\begin{array}{c}\text { 纬度 } \\
\text { Latitude }\end{array}$} & \multicolumn{11}{|c|}{ 经度 Longitude } \\
\hline & $79^{\circ}$ & $80^{\circ} \sim 82^{\circ}$ & $82^{\circ} \sim 84^{\circ}$ & $84^{\circ} \sim 86^{\circ}$ & $86^{\circ} \sim 88^{\circ}$ & $88^{\circ} \sim 90^{\circ}$ & $90^{\circ} \sim 92^{\circ}$ & $92^{\circ} \sim 94^{\circ}$ & $94^{\circ} \sim 96^{\circ}$ & $96^{\circ} \sim 98^{\circ}$ & $99^{\circ}$ \\
\hline $35^{\circ} \sim 34^{\circ}$ & 11.57 & 10.27 & & & & & & & & & \\
\hline $34^{\circ} \sim 33^{\circ}$ & 15.32 & 13.89 & & & & & & & & & \\
\hline $33^{\circ} \sim 32^{\circ}$ & 18.05 & 17.19 & & & & & & & 17.35 & 28.86 & \\
\hline $32^{\circ} \sim 31^{\circ}$ & 17.85 & 16.55 & & & & & & 35.12 & 42.30 & 50.72 & 35.68 \\
\hline $31^{\circ} \sim 30^{\circ}$ & 13.28 & 19.35 & 10.15 & & & 25.72 & 41.29 & 49.15 & 62.46 & 81.39 & 63.17 \\
\hline $30^{\circ} \sim 29^{\circ}$ & & & & 42.67 & 38.17 & 77.69 & 84.71 & 68.26 & 53.29 & 61.27 & 58.92 \\
\hline $29^{\circ} \sim 28^{\circ}$ & & & & 56.27 & 65.69 & 65.86 & 58.76 & 83.12 & 49.19 & 59.72 & 50.02 \\
\hline $28^{\circ} \sim 27^{\circ}$ & & & & 48.90 & 48.88 & & & 56.87 & & & \\
\hline $26^{\circ}$ & & & & & & & & 48.76 & & & \\
\hline
\end{tabular}

分布于 $28^{\circ} \sim 30^{\circ} \mathrm{N} \times 88^{\circ} \sim 94^{\circ} \mathrm{E}$ 的 3 个小区的 栽培大麦资源数为 1937 份 (表 2) ,占西藏栽培大麦 地方品种资源数 3204 份的 $60.46 \%$, 每小区占有量 为 323 份, 是总小区平均数 74.5 份的 4.33 倍, 且多 样性指数较高 (表 3 ), 平均为 4.98 , 是各小区平均多 样性指数 4.19 的 1.19 倍。此外, 在 $30^{\circ} \sim 31^{\circ} \mathrm{N} \times$ $96^{\circ} \sim 98^{\circ} \mathrm{E}$ 的一个小区, 资源份数为 278 份, 占西藏 栽培大麦地方品种总数 3204 份的 $8.67 \%$,多样性 指数为 7.89 ,明显高于四周其它小区。综合变异系 数的地理分布与遗传多样性指数相类似 (表 4)。也 在 $28^{\circ} \sim 30^{\circ} \mathrm{N} \times 88^{\circ} \sim 94^{\circ} \mathrm{E}$ 的 3 个小区和 $30^{\circ} \sim 31^{\circ} \mathrm{N}$ $\times 96^{\circ} \sim 98^{\circ} \mathrm{E}$ 的 1 个小区形成栽培大麦的综合变异 系数高值区。由此随着向四周延伸距离的增大, 变 异系数则逐渐减少。

\section{3 结论与讨论}

\section{1 西藏栽培大麦的遗传多样性中心}

通过对 3204 份西藏栽培大麦 11 个性状、3个 指标的比较分析可以看出 (表 $2 \sim 4$ ) :不论西藏栽培 大麦的品种数量, 还是遗传多样性指数和变异系数, 均有明显的区域分布特点。即西藏 $28^{\circ} \sim 30^{\circ} \mathrm{N} \times 88^{\circ}$ $\sim 94^{\circ} \mathrm{E}$ 区域和 $30^{\circ} \sim 31^{\circ} \mathrm{N} \times 96^{\circ} \sim 98^{\circ} \mathrm{E}$ 区域形成明 显的两个遗传多样性中心, 其中 $28^{\circ} \sim 30^{\circ} \mathrm{N} \times 88^{\circ} \sim$ $94^{\circ} \mathrm{E}$ 区域拥有西藏栽培大麦资源份数最多, 遗传多 样性丰富, 而且该区域是藏文化的发祥地, 农耕历史 悠久,分布有极为丰富的野生大麦资源, 这里可能是 西藏栽培大麦的初生多样性中心; 在 $30^{\circ} \sim 31^{\circ} \mathrm{N} \times$ $96^{\circ} \sim 98^{\circ} \mathrm{E}$ 区域 地处藏东三江( 金沙江、怒江、澜沧 江)流域的横断山脉一带, 这里栽培大麦资源搜集数 量、遗传多样性及综合变异系数均较高, 仅次于藏中 大麦遗传多样性中心。因此, 可推测西藏栽培大麦 形成了不均衡的两个多样性中心。

\section{2 西藏栽培大麦遗传多样性扩散}

在对西藏栽培大麦遗传多样性中心和分析的基 础上, 进一步讨论西藏栽培大麦多样性的扩散问题。 根据 Vavilov 和 Harlan 关于 每一种作物都有一个独 特的多样性初生中心, 这也就是它的分化中心, 这种 中心往往在进化的起始阶段就扩散到较大的区域， 其分布是地理学上的连续原一体”的理论 (董英山, 2000），并根据作物一般由生物多样性丰富区向次丰 富区传播的趋势, 可以推测西藏栽培大麦有两种可 能的扩散模式。一种可能是从藏中栽培大麦多样性 
初生中心开始。这里丰富的遗传多样性蕴藏着极大 的遗传潜能,在西藏高原的环境选择及环境变化造 成的基因突变影响下,形成新的生态类型。从初生 中心开始，向西传播至克什米尔及中亚地区，向南到 达印度一带, 向东到达横断山脉一带, 进一步分化 后，再沿长江流域和黄河流域传播。另一种可能是， 西藏栽培大麦同时存在着遗传多样性不等的 2 个分 化中心, 即藏中分化中心和藏东分化中心, 再由这 2 个中心同时向四周扩散形成东方型大麦的分布与类 型。

由本文据大麦遗传多样性提出的西藏栽培大麦 多样性扩散模式的推断, 为栽培大麦的扩散提供了 一个重要依据。但由于本研究只涉及 11 个性状 结 果是否正确有待于分子水平的进一步研究证实。

\section{参 考 文 献}

Dong, Y.S. (董英山), B. C. Zhuang (庄炳昌), L. M. Zhao（赵 丽梅), H. Sun (孙寰), M. Zhang (张明) \& M. Y. He(何孟 元). 2000. Genetic diversity centers of annual wild soybean in China. Acta Agronomica Sinica (作物学报), 26: $521 \sim 527$. (in Chinese with English abstract)

Fu, D.X. (傅大雄), R. W. Ruan(阮仁武), X. M. Dai (戴秀梅) \& Y.M.Liu(刘咏梅) .2000. A study on ancient barley, wheat and millet discovered at Changguo of Tibet. Acta Agronomica Sinica (作物学报), 26:392 398. (in Chinese with English abstract) Ma,D. Q. (马得泉). 2000. Genetic resources of Tibetan barley in China. Beijing: China Agricultural Press. $38 \sim 60,155 \sim 156$. (in Chinese)
Ma,D.Q. (马得泉) \& X.L. Qiang(强小林). 1991. Studies on ecological distribution of barley in Tibet. In: Barley Committee, Chinese Crop Science Association ed. The ecological distribution of cultural barley in China. Hangzhou: Hangzhou Science and Technology Press. 178 193. (in Chinese)

Ma,D.Q. (马得泉) \& T. W. Xu(徐廷文). 1987. Studies on taxonomy of cultural barley in Tibet. In: Academy of Tibetan Agricultural and Animal Husbandry College ed. The inspectoral collect works of varietied resources of crop in Tibet. Beijing: China Agricultural Press. 40 69. (in Chinese)

Wang, H. J. (王恒杰) . 1975. The historial remains of new Neolithic age discovered at Linzhi county of Tibet. Archaeology (考古), 5: $310 \sim 315$. (in Chinese)

Wang,Z.H. (王宗华). 1992. The studies make progress of resistance genet and breeding to Yellow rust. Tibet's Science and Technology (西藏科技), 17(4):24 26. (in Chinese with English abstract)

Xu, T. W. (徐廷文). 1982. Varietied appraisal and taxonomy of cultural barley in China. Scientia Agricultural Sinica(中国农业 科学), 15(6): 39 47. (in Chinese with English abstract)

Za,S. (扎桑) \& X. M. Wang(王先明). 1991. The varieties of cultural barley and its ecological distribution in Tibet. In: Barley Committee, Chinese Crop Science Association ed. The ecological distribution of cultural barley in China. Hangzhou: Hangzhou Science and Technology Press. $194 \sim 209$. (in Chinese)

Zhan, X.Y.(湛小燕),Z.L. Yu(俞志隆) \& P.Z. Huang (黄培 忠).1991. Studies on polypeptide characteristics of prelamine in Chinese barley. Acta Genetica Sinica (遗传学报), 18:252 262. (in Chinese with English abstract)

Zhang, Q. F. (张启发), X. K. Dai (戴先凯) \& M. A. Saghai Marorf. 1992. Comparative assessment of genetic variation at 6 isozyme loci in barley from two genters of diversity: Ethiopia and Tibet. Acta Genetica Sinica (遗传学报), 19:256 243. (in Chinese with English abstract) 